\title{
Hibriditeit in "Kameelperd" Goties geteken
}

\author{
Marthinus P. Beukes \\ Departement Afrikaans \\ Universiteit van die Noordweste \\ MMABATHO
}

\section{Abstract \\ Gothic illustration of hybridity in "Kameelperd"}

In this article it is argued that the premise of linguistic and conceptual elements in a poem serves as a focal point for the reader's interpretation. A single text i.e. "Kameelperd" of Cloete is taken as an example to show that cohesion between various textual elements is interwoven to result in a unity. Textual cohesion relying on similarities in grammatical and lexical criteria proves the relation between elements which enable the author to draw an illustration of a giraffe by means of language. Coherence is proved to have taken place when the connection between cohesive elements in the text is actualised through the reader's process of reading and interpreting. It becomes evident that the giraffe in this poem is portrayed and drawn by the context of linguistic elements in the poem.

\section{Inleiding: vooropstelling, kohesie en koherensie}

Verskillende taal- en konseptuele elemente kan in 'n literêre teks vooropgestel wees. Met vooropgestelde elemente kan die aandag gevestig word op belangrike spilpunte van die teks. Aangesien daar egter in die gedig soveel verweefde taal-, konseptuele en komposisionele manifestasies is, is daar 'n verskeidenheid vooropgestelde fokuspunte. Dit impliseer egter dat verskillende lesers verskillende vooropgestelde fokuspunte gaan 'raaksien'. In die lig hiervan is die leser se 'raaklees' van die vooropgestelde element in die gepaardgaande integrering met die res van die gedigelemente 'n dinamiese handeling. Vooropstelling rig dus die leser se leesaksie en lei hom tot verbandlegging. Verbandlegging as dinamiese handeling is die integrale leesaksie van koherensie, maar dit is gebou op die kohesiewe tekstuur van 'n (gedig)teks. Die leser se koherente verstaan van 'n poësieteks word dus gerig deur die raaklees van vooropgestelde elemente wat tekskohesief is. Hierdie werkswyse is veral by die onderrig van letterkunde bruikbaar by nie- 
moedertaalsprekers, want die leser word in staat gestel om 'n praktiese metode te bemeester om te verstaan hoe tekste werk en hoe die inhoud geïnterpreteer kan word.

Halliday en Hasan (1976:11) praat van kohesie wanneer een element in die teks verwys na 'n voorafgaande element of 'n element wat nog gaan volg. 'n Verband kom dan tot stand tussen sulke elemente wat veral op grammatikale vlak in 'n teks voorkom. Kohesie veronderstel dus 'n verhouding tussen tekselemente wat gebind word deur middel van besondere strukturele assosiasies (Vuchinich, 1977:232). 'n Netwerk grammatikale verbintenisse ontstaan in 'n teks wanneer twee of meer tekselemente ten opsigte van betekenis op mekaar aanspraak maak. Kohesie is derhalwe 'n saak wat sterk aanspraak maak op ooreenkomste op grammatikale en leksikale vlak. Binding wat dus in 'n teks voorkom, kan op leksikografiese, grammatikale, fonologiese en semantiese vlakke wees. Kortom: wanneer twee (of meer) tekselemente ten opsigte van betekenis op mekaar aanspraak maak, is daar sprake van kohesie.

Dominansie van ('n) element(e) het 'n semantiese funksie, maar is nie in isolasie waarneembaar nie; dit staan in verband met ander sake/elemente in 'n teks. Die geheel kan nie genegeer word nie, want, sê Amheim (1974:11): "No object is perceived as unique or isolated. Seeing something involves assigning it a place in the whole." 'n Teks is dus 'n eenheid wat opgebou is deur die verweefdheid van die tekselemente. Cloete (1982a:26) poneer tereg dat "betekenis in die gedig impliserend (is) omdat die betekenis nie selfstandig en reglynig kan uitpraat nie maar rekening moet hou met ander manifestasievorms". Dié holistiese eienskap van 'n teks hang ook saam met die koherensie of samehang tussen die elemente. Met die volgende woorde bevestig Cloete (1982a:45/46) die wesenseienskap van 'n poësieteks waarbinne die samehang (dus koherensie - MPB) tussen elemente voorkom:

Dit gaan nie daarom of die gedig dit of dat het (outeur se kursivering - MPB) nie, maar om vas te stel wat dit of dat doen, en in samewerking met die ander elemente, en omdat alle elemente in 'n gedig sáámdoen, omdat alle kommunikatiewe of manifestasievorme in 'n gedig uiteindelik dieselfde ding sê, al sê hulle dit meervoudig, moet ons uiteensetting en beskrywing van die gedig, gevolglik ook ons evaluering, integraal of integrerend wees: hóé en wat doen en sê die elemente sáám.

Die "samewerking" of "saamdoen" van elemente is gewoon kohesiewe ooreenkomste tussen elemente wat deur die interpretasieproses van die leser tot samehang gebind word (soos Cloete sê: "hóé en wat doen en sê die elemente sáám"). Aangesien die vooropgestelde elemente aan die leser 'wenke' gee oor 
hoe kohesie raakgelees moet word, rig en stuur dit ook sy interpretasieproses. Koherensie kan dus gedefinieer word as die samehang tussen alle kohesiewe elemente in 'n teks wat deur middel van die lees- en interpretasieproses geaktualiseer word. Deur middel van hierdie samehang ontstaan tekstualiteit waardeur die leser gerig word om diskoerssamehang raak te lees.

\section{2. "Kameelperd" - hibridiese dier Goties gedig}

Dit is veral in die gedig "Kameelperd" in Jukstaposisie (p. 41) so dat die vooropstelling (lees dominansie - MPB) én kohesie tussen sekere struktuurelemente 'n koherente teksinterpretasie tot gevolg het. Die gedigteks is 'n wyse om deur middel van taal 'n illustrasie te gee van die kameelperd. In terme van Peirce kan van ikonisiteit gepraat word, want die inhoud van die teks word in die struktuur gemanifesteer. Hierdie manifestasie is betekenisvol, want die gelykenis wat tot stand kom tussen die teken en die gedenoteerde objek (Cloete \& Wybenga, 1992:179) is visueel vasstelbaar.

\section{Kameelperd}

$\begin{array}{ll}1 & \text { hy lýk so melankoliek } \\ 2 & \text { as hy buk of hardloop gerafiek } \\ 3 & \text { is hy as hy loop of staan hierdie } \\ 4 & \text { wonderlikste enigste dierlike Gotiek }\end{array}$

Vooropstelling van vreemde woordkombinasies en woordbetekenisse trek die leser se aandag in hierdie gedig. Die gevolg hiervan is semantiese vooropstelling wat as 't ware ikoniese duiding kry aangesien die objek, kameelperd, afgebeeld en geteken word deur die taalmatige elemente.

Die kameelperd se spesienaam is Giraffa camelopardalis (Ryke, 1975:694). Hierdie Griekse naam is 'n samevoeging en assosiasie tussen 'n aantal diere, naamlik die kameel, luiperd en perd. Die oorspronklike naam Cameleopardia het ontstaan uit die legende dat die kameelperd 'n kruising tussen 'n kameel en 'n luiperd is vanwee die kameelvorm en geelwitkleur met reëlmatige rye donkerbruin of swart vlekke - 'n gegewe wat met 'n luiperd geassosieer word (Van Niekerk, 1984:33). In die titel van die gedig word assosiasies met ander diere geïmpliseer ten opsigte van uiterlike ooreenkomste. Dié vooropgestelde assosiatiewe gegewe tussen diere kan in Venter (1988:115) se woorde saamgevat word:

Die titel dra in sy samegesteldheid reeds die boodskap van hibriditeit deur die kruising van verskillende (dier)rasse. Tog word hierdie hibriditeit op aanskoulike wyse geteken vir die leser deur dit met 'n Gotiese katedraal te 
assosieer wat 'in de bouw van gewelven grote mate van constructieve volmaaktheid bereikt' (Anon., 1969:776).

Hibriditeit kom ook op taalvlak voor, want vreemde woordvorme is in dié gedig vooropgestel. So byvoorbeeld kan vooropstelling gesien word in "gerafiek" waarin die Engelse sinoniem vir kameelperd giraffe $e^{l}$ byvoorbeeld gebruik word en klankmatig kohesief is met "Gotiek" . Die woord gerafiek word vreemd gebruik en daarom vooropgestel. Die Griekse spesienaam maak die lê van verbande moontlik. Semantiese vooropstelling word verkry deur die vreemde en ongewone gebruik van die woord gerafiek. Die woord is hier as adjunk gebruik en wyk af van die oorspronklike gebruik daarvan as substantief. Die kameelperd word deur die woord beskryf, ook deurdat dit dui op grafiek, wat as die uiterlike vorm van die kameelperd beskou kan word. Hierin lê die ikonisiteit van die kameelperd, want die dier word grafies gebeeld deur die teken "grafiek". Tog word die woord nie alleen deur die tipografiese ooreenkoms tussen teken en objek vooropgestel nie, maar ook deur die sintaktiese plasing van die woord aan die einde van die versreël. Die woord word sodoende semanties en sintakties vooropgestel.

Die leser kan 'n visuele beeld van die kameelperd aan die hand van die uiterlike beskrywing, woordbetekenis en sintaksis vorm. Dit kan byvoorbeeld gesien word as grafiek uit "gerafiek" gelees word. Verdere verbeelding van die kameelperd word bereik deur klankooreenkomste tussen "melankoliek", "hierdie" en "dierlike Gotiek". Dié klankkohesie vorm 'n grafiese voorstelling van die kameelperd as al die [i]-klanke met 'n lyn verbind sou word. Klankikonisiteit kom dus voor as die klanke 'n grafiek van die kameelperd trek. Deur klank- en sintaktiese kohesie kan die leser die vooropgestelde elemente raaklees en 'n interpretasieaanknooppunt met die teks kry.

Die grafiese tekening van die kameelperd word ook deur die herhaling van die voornaamwoorde vooropgestel. Word die "hy"-woorde as punte op papier gesien en verbind met mekaar, blyk nog 'n kameelperdgrafiek (Lugthart, 1983). Lugthart wys verder op die vorm van die letters " $h$ " en " $y$ " wat óók die visuele beeld van die kameelperd vooropstel. Selfs in die mikrogegewe van die gedigklank word die visuele beeld vooropgestel en gerugsteun.

As die uiterlike bou van die kameelperd voor oë gehou word, is die sienings van die grafiese nie vergesog nie. Die kameelperd word deur Storer et al. (1972:813-814) beskryf as: "Neck and legs very long ... 5.5 to $6 \mathrm{~m}$ (18 to $20 \mathrm{ft})$

1 Die woord giraffe is afgelei van die Arabiese woord zarafa wat beteken "one who walks swiftly" (Anon., 1971:430). 
tall". Dié ongewone voorkoms van die kameelperd word in die morfologie, woordvorm en -betekenis en fonologie vooropgestel. Die suprasegmentele klem in "lýk" dra by tot die visuele vooropstelling van die kameelperd. Du Plessis (1983:158) wys daarop dat "nadruk" (waaronder klem val) 'n element in die kommunikasieaanbod is waardeur "groter kommunikatiewe gewig" (sy onderstreping) gegee word, veral in sekere sintaktiese en fonologiese prosesse. Die kommunikatiewe gewig van "lýk" word dus met die gebruik van relevering verhoog. Die visuele lê alreeds vooropgestel in die woord, want daarin is fokus op uiterlike ooreenkomste geplaas.

Die visuele "lýk" word verder benadruk, want die ooreenkoms tussen "grafiek" en "Gotiek" is nie nét na aanleiding van klankkohesie nie, maar ook vanweë die ongewone gebruik daarvan.

Die verdierliking van "Gotiek" is ook vooropgestel. Nie alleen is daar op die kameelperd 'n betekenisoordrag van die Gotiese nie, maar ook van 'n verdierliking van die boustyl. "Gotiek" beteken volgens Van Dale (1977:29) "door spitsbogen gekarakteriseerde bouwstijl". Die Gotiese boustyl het in die twaalfde eeu in Noord-Frankryk ontstaan (Van Dale, 1977:290), en het 'n verreikende invloed op die argitektuur gehad. Veral op religieussimboliese vlak het dié boustyl weerklank gevind, want Gotiese katedrale is gebou met drie vlakke om die Drie-eenheid voor te stel. Ook het die katedrale 'n gepunte vorm gehad wat bedoel was om die oog hemelwaarts te lei (Van Jaarsveld, 1993:102). 'n Kombinasie van verheerliking én versiering ${ }^{2}$ is ook aanwesig, want die boustyl getuig verder van 'n oormaat verfraaiing en versiering.

Die oordrag van die boustylvorm op die kameelperd wil beklemtoon dat hy óók oormatig verfraai is met sy "lýk". Soos Lugthart (1983) opmerk, is die kameelperd se kop te klein in verhouding met die res van die liggaam, sy pote en nek is te lank en beweeg hy moeisaam en stokkerig. Dié beskrywing van die kameelperd belig ook die fonologiese, leksikale en semantiese kohesie tussen "melankoliek", "grafiek" en "Gotiek". Die koherensie wat die leser op grond van hierdie woordgebruik raaklees, is daarom geregverdig, want dié woorde is dus nie net op betekenisvlak gebind nie, maar ook op fonologiese en sintaktiese vlakke.

Van Niekerk (1984:34) kombineer die drie woorde onder die woord "trilogie": 'n drieledigheid wat óók in die Griekse naam van die kameelperd, Giraffa camelopardalis, eggo. Die kameelperd word dus na aanleiding van sy uiterlike bou beskryf as 'melankoliek', (want die mens is immers geneig tot

Lees ook as hibriditeit. 
melankoliese buie), 'grafies' en 'Goties' (hy werk met grafieke en ontwerp en bou Gotiese geboue). Vanaf die pronomen "hy" (óók drie maal gebruik) is die menslike element gesuggereer. Nóg 'n verdere vorm van hibriditeit word sodoende gestig. Die lesing word ook gerig deur die woordjie "lýk", want al die toepassings geskied omdat die kameelperd na menslike vorms en houdings "lýk". Só word die kameelperd ikonies geteken, want die inhoud van die gedig is op 'n verskeidenheid vlakke in die gedig gemanifesteer.

Strukturele vooropstelling word voltrek in die woord "Gotiek" aan die einde van die gedig. Aangesien die woord die enigste hoofletterwoord in die gedig is, is dit vooropgestel. Verder staan die woord aan die einde van die gedig wat 'n vooropgestelde sintaktiese posisie ${ }^{3}$ in 'n versreël is. Deur die demonstratief "hierdie" word "Gotiek" verder semanties benadruk, want die unieke aard van die kameelperd word daardeur aan die leser voorgehou. Die vooropstelling van "Gotiek" word nóg verder gevoer deur 'n stadige ritme as gevolg van die opeenhoping van adjektiewe:

\section{... hierdie \\ wonderlikste enigste dierlike Gotiek}

Die leser kan nie anders as om deur die herhaling van die adjektiewe stadiger te lees en die spanning te voel vir die substantief "Gotiek" wat so oordadig beskryf word nie. Deur hierdie opeenhoping van adjektiewe word die oordadigheid van die Gotiese boustyl dubbelkragtig op die kameelperd gefokus. Die kameelperd word dus deur die assosiasies van "Gotiek", maar ook deur die woordherhalings, oordadig deur die digterlike woord verfraai. Die drie vlakke van die Gotiese katedraal om die Drie-eenheid voor te stel, word ook in die slotreël verdig deur die drie adjektiewe. Só word die kameelperd dus ook 'n 'konstruksie' wat die Drie-eenheid op hierdie vlak in die gedig kan voorstel deur taal- en tektoniese manifestasie. Alle elemente in die gedig is sáám 'n Gotiese katedraal ${ }^{4}$ wat gekenmerk word deur "één organisch geheel, waarvan alle delen samen behoren en geen gemist kan worden" (Anon., 1969:776).

Klankooreenkomste tussen die drie woorde "melankoliek", "gerafiek" en "Gotiek" is nóg 'n wyse van vooropstelling waardeur die leser die kameelperd voor oë kan stel. Die grafiese en Gotiese uiterlike van die kameelperd word ook sintakties vooropgestel. Die drie beskrywende woorde ("melankoliek", "gerafiek" en "Gotiek") is paradigmaties vooropgestel (vergelyk A hiernaas),

3 Vergelyk Giora (1983 en 1985) in dié verband.

Vergelyk Van Jaarsveld (1993) in die lig hiervan. 
want dié woorde kom paradigmaties of vertikaal in die gedig voor. Sintagmatiese ooreenkoms (vergelyk B) tussen die woorde "wonderlikste", "enigste" en "dierlike" beskryf ook die kameelperd:

\begin{tabular}{|c|l|}
\hline A & melankoliek \\
\hline & gerafiek \\
\hline & Gotiek \\
\hline
\end{tabular}

\begin{tabular}{|c|c|c|c|}
\hline \hline $\mathrm{B}$ & wonderlikste & enigste & dierlike \\
\hline
\end{tabular}

Leksikale herhalings waardeur die kameelperd beskryf word, is saamgevat in (A) en (B). Sy uiterlike bou en geaardheid word daardeur gekwalifiseer. Herhaling is hier 'n wyse om voorop te stel en woorde te bind. So word die leser hierdeur as 't ware, met die raaklees van die herhalings, gedwing om koherente verbande te lê. Dit is opvallend dat die paradigmatiese en sintagmatiese ooreenkomste tussen die kameelperdbeskrywende woorde óók 'n grafieklyn vorm.

Die herhalingswoorde "buk of hardloop" en "loop of staan" het 'n verdere vooropstelling tot gevolg. Die statiese en dinamiese handelingswoorde dra by om die sukkelende beweging van die kameelperd te beskryf en te skets in dié woordooreenkomste:

\begin{tabular}{|l|l|l||}
\hline buk & of & hardloop \\
\hline staan & of & loop \\
\hline - dinamies & & + dinamies \\
\hline
\end{tabular}

Venter (1988:116-117) dui ook die beweging van die kameelperd aan deur die werkwoorde wat kruisgekoppel word: 
'n Houdings- en bewegingsverandering met die opvallende kruisverhouding:

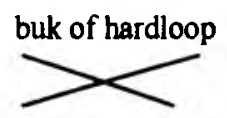

loop of staan

verander die oënskynlik negatiewe in 'n kontrasterende, syn, naamlik 'gerafiek'.

Word die woord "staan" - na aanleiding van aktiwiteit - in die matrys gelees, is dit 'n verdere voorbeeld van die sukkelende aard van die kameelperd. Die handelingswoorde dra dus verder by om die kohesie van uiterlike dinge van die kameelperd voorop te stel.

\section{Samevatting}

In dié klein gedig is byna elke woord semanties, fonologies, sintakties en morfologies kohesief. Kohesie is dus op byna alle taalvlakke in die teks ontgin. 'n Koherente lesing hiet tot stand gekom deurdat die leser die vooropstelling van die woordvorme, woordsamestellings en woordherhalings raakgesien en met mekaar in verband gebring het. Die leser is dus ook bouer aan die Gotiese konstruksie van taal, want soos boustene pas die een eenheid uitbreidend op die volgende, om uitendelik te lei tot 'n nuwe saamgestelde struktuur'.

\section{Bibliografie}

Anon. 1969. Gotiek. In: Kleine Winkler Prins. Amsterdam : Elsevier. 2:776-777.

Anon. 1971. Giraffe. In: Encyclopaedia Britannica. Micropaedia, 10:430.

Amheim, R. 1974. Art and Visual Perception: A Psychology of the Creative Eye. Berkeley, New York : University of California Press.

Cloete, T.T. 1982a. Hoe om 'n gedig te ontleed. Pretoria : Academica. (Reuseblokboek 6.)

Cloete, T.T. 1982b. Jukstaposisie. Kaapstad : Tafelberg.

Cloete, T.T. \& Wybenga, G. 1992. Ikoon en ikonisiteit. In: Cloete, T.T., (red.). Literêre terme en teorië. Pretoria : HAUM-Literêr. p. 178-182.

De Tollenaere, F. \& Persijn, A.J. 1977. Van Dale: nieuw handwoordenboek der Nederlandse taal. 's Gravenhage : Martinus Nijhoff.

5 Kyk in dié verband Van Jaarsveld (1993:105). 
Du Plessis, H. 1983. Die verband tussen taal en letterkunde. In: Sinclair, A.J.L. (red.). G.S. Nienaber - 'n huldeblyk. Bellville : Universiteit van Wes-Kaapland. p. 157-166.

Giora, R. 1983. Segmentation and Segment Cohesion: on the Thematic Organization of the Text. Text, 3(2):155-181.

Giora, R. 1985. Notes towards a Theory of Text Coherence. Poetics Today, 6 (4):699-715.

Gräbe, I. 1983. Seminaar oor Jukstaposisie. Potchefstroom : PU vir CHO. (Ongepubliseer.)

Halliday, M.A.K. \& Hasan, R. 1976. Cohesion in English. London : Longman.

Lugthart, A. 1983. In: Gräbe, I. Seminaar oor Jukstaposisie gehou te Potchefstroom, onder voorsitterskap van prof. Ina Gräbe. (Ongepubliseer.) Ryke, P.A.J. 1975. Dierkunde: 'n funksionele benadering. Durban : Butterworth.

Storer, T.I., Usinger, R.L., Stebbing, R.C. \& Nybakken, J.W. 1972. General Zoology. New York : MacGraw-Hill.

Van Dale $k y k$

De Tollenaere, F. \& Persijn, A.J., (reds.)

Van Niekerk, F. 1984. Die motto in Jukstaposisie. Ensovoort, 4(1):30-35, Mei.

Venter, I.L. 1988. Intergedigtelike verhoudings in die poësie van T.T. Cloete, met Jukstaposisie as vertrekpunt. Pretoria : UP. (D.Litt.-proefskrif.)

Vuchinich, S. 1977. Elements of Cohesion between Turns in Ordinary Conversation. Semiotica, 20 (3/4):229-238.

Van Jaarsveld, A.E. 1993. Driepas (T.T. Cloete)-die digter as dissipel; die taal as katedraal. Mmabatho : UNIBO. (D.Litt.-proefskrif.) 